\title{
High Soybean Yield and Drought Adaptation Being Associated with Canopy Architecture, Water Uptake, and Root Traits
}

\author{
Xiu-Bing Gao ${ }^{1,2}{ }^{-}$, Can Guo $^{2}$, Feng-Min $\mathrm{Li}^{3 \oplus}{ }^{-}$, Ming $\mathrm{Li}^{1, *}$ and $\mathrm{Jin} \mathrm{He}^{1,4, * \mathbb{C}}$ \\ 1 The Provincial Key Laboratory for Agricultural Pest Management in Mountainous Region, Institute of Crop \\ Protection, College of Agriculture, Guizhou University, Guiyang 550025, China; gxb527@163.com \\ 2 Guizhou Tea Research Institute, Guizhou Province Academy of Agricultural Science, Guiyang 550006, China; \\ cancan.good@163.com \\ 3 State Key Laboratory of Grassland Agro-ecosystems, Institute of Arid Agroecology, School of Life Sciences, \\ Lanzhou University, Lanzhou 730000, China; fmli@lzu.edu.cn \\ 4 The Key Laboratory of Plant Resource Conservation and Germplasm Innovation in Mountainous \\ Region (Ministry of Education) College of Agriculture, Guizhou University, Guiyang 550025, China \\ * Correspondence: lm21959@163.com (M.L.); hejin0811@163.com (J.H.)
}

Received: 16 March 2020; Accepted: 21 April 2020; Published: 24 April 2020

\begin{abstract}
Water stress is the main abiotic factor that limits soybean grain yield. We investigated eight soybean cultivars under well-watered (WW) and terminal drought stress (TDS) conditions to determine the traits associated with water saving and the relationship between water use, root morphology, canopy architecture, flower and tagged-pod number, and yield performance. Under WW conditions, the average grain yield across the new soybean cultivars was significantly higher (18.7 g plant $^{-1}$ vs. $\left.15.1 \mathrm{~g} \mathrm{plant}^{-1}\right)$, but significantly less water was used ( $36 \mathrm{~L} \mathrm{plant}^{-1}$ vs. $47 \mathrm{~L} \mathrm{plant}^{-1}$ ) than in the old soybean cultivars. Under TDS, the four old soybean cultivars failed to produce a measurable grain yield, while the new soybean cultivars Zhonghuang $30(\mathrm{ZH})$ and Jindou 19 (J19) produced a measurable grain yield. Water stress significantly reduced the flower numbers and tagged-pod numbers; the four new soybean cultivars on average had low flower and tagged-pod numbers under WW treatment, while they had low flower but high tagged-pod numbers under TDS conditions. ZH and JD exhibited a lower branch number and leaf area under both WW and TDS conditions. Water use during the flowering and podding periods was significantly positively correlated with the flower number and the tagged-pod number under both WW and TDS conditions. Thus, the small canopy size and low root length and root surface area contributed to a water-saving mechanism in the new soybean cultivars and improved the yield under drought conditions.
\end{abstract}

Keywords: water use; terminal drought; flower number; water-saving mechanism

\section{Introduction}

Soybean (Glycine max (L.) Merr.) yield and yield stability are constrained by drought [1]. These yields could be further threatened by drought, as drought events are predicted to increase in the future [2]. Tremendous efforts in soybean breeding have been conducted to improve drought tolerance, with the primary goal of enhancing yield under drought. Although soybean yield has been increased significantly by traditional breeding efforts, the underlying mechanisms are unclear.

Previous studies showed the pattern of water extraction/use is crucial for crops growing under limited water resources [3,4]. Water shortages during flowering and/or podding stages could reduce the flower and pod number and increase pod and flower abortion, with a large impact on seed yield $[5,6]$. Increasing water use at the grain filling stage contributes to yield under a terminal drought by reducing 
water use at the vegetative stage, as reported for crops such as chickpea [7-9], cowpea [10], and pearl millet [11]. In a recent study, Borrell et al. [12] showed that increasing the post-anthesis drought adaptation was associated with reducing the canopy size and pre-flowering water use. However, the role of the canopy size in determining water use in different soybean genotypes is unknown.

In terms of demand, crop water use can be reduced by decreasing the leaf area and/or transpiration rate per unit leaf area. Transpiration per unit leaf area can be limited by stomatal density or aperture, the timing of stomatal opening, and hydraulic factors. In terms of supply, increasing water accessibility could increase water use at the grain filling stage [13].

Roots are the main organs that absorb water from the soil, which indicates a strong potential for improvement of drought resistance through breeding [1], and a number of root-related traits, such as root distribution and root density, have been proposed as indicators of drought tolerance in soybean [14-16]. As previous studies showed that extracting water slowly was one way to reduce water use, it is important to determine the relationship between the root traits and water uptake. Further clarification of the role of root traits requires precise water extraction data. Root assessment, particularly during the vegetative stage, may not reflect differences in water uptake at key stages such as grain filling; therefore, whether the root morphology traits relate to water extraction is worth investigating.

Our previous study showed that modern soybean cultivars have significantly higher grain yield than old soybean cultivars under rainfall conditions in the field [17]. In this study, canopy size, root morphology traits, water use, yield, and yield components in eight cultivars under two water regimes were compared to investigate (1) the role of canopy size in determining water use in different soybean genotypes and (2) whether root morphology traits are related to water extraction.

\section{Materials and Methods}

\subsection{Materials and Growth Conditions}

Experiments were conducted in 2014 during the growing season at the Yuzhong Experiment Station of Lanzhou University in Yuzhong County, Gansu Province $\left(35^{\circ} 51^{\prime} \mathrm{N}, 104^{\circ} 07^{\prime} \mathrm{S}\right.$, altitude $1620 \mathrm{~m}$ ). We selected four modern soybean cultivars bred in different eras (Jindou 19 (J19, released in 2003), Jidou 12 (Ji, released in 2006), Zhonghuang ( $\mathrm{ZH}$, released in 2006), and Jindou 21 (J21, released in 1999)) and four old soybean cultivars with a similar phenology (Huangsedadou (HD), Longxixiaohuangpi (LX), Bailudou (BLD), and Xiaoheidou (XHD)). Table 1 displays the traits of each soybean cultivar. Soybean seeds were initially placed in water containing $5 \mathrm{~g} / \mathrm{L}$ carbendazim for $10 \mathrm{~min}$ before sowing. Two seeds were sown in each pot containing a sieved Loess soil-based substrate (Loess soil:vermiculite (v:v) = 3:1). Before sowing, $0.19 \mathrm{~g}$ of $\mathrm{N}$ per $\mathrm{kg}$ dry soil, $0.13 \mathrm{~g}$ of $\mathrm{K}$ per $\mathrm{kg}$ dry soil, and $0.11 \mathrm{~g}$ of $\mathrm{P}$ per $\mathrm{kg}$ dry soil were added to the substrate to ensure adequate nutrition throughout the experiment. After germination, seedlings were thinned to one per pot. All pots were weighed and watered to maintain the soil/water content at about $80 \%$ field water content (FC). Black plastic sheets were placed over the cylinders to prevent water loss by soil evaporation. In this study, 96 pots made by PVC tubes that are $0.16 \mathrm{~m}$ in diameter and $1.33 \mathrm{~m}$ long were used; a complete random design was used, and all the pots were moved weekly to avoid the side effect. All pots were located in the rain shelter.

Table 1. Characteristics of the eight soybean cultivars used in this study.

\begin{tabular}{ccccc}
\hline Cultivars & Location & Breeding Year & Days To Maturity & Characteristics \\
\hline Huangsedadou (HD) & Gansu & Landrace variety & 147 & small seed, low yield \\
Longxixiaohuangpi (LX) & Gansu & Landrace variety & 149 & small seed, low yield \\
Bailudou (BLD) & Shanxi & Landrace variety & 151 & small seed, low yield \\
Xiaoheidou (XHD) & Shanxi & Landrace variety & 148 & small seed, low yield \\
Jindou 21 (J21) & Shanxi & 1999 & 145 & medium seed, high yield \\
Jindou 19 (J19) & Shanxi & 2003 & 140 & large seed, high yield \\
Jidou 12 (Ji) & Hebei & 2006 & 151 & large seed, high yield \\
Zhonghuang 30 (ZH) & Beijing & 2006 & 140 & large seed, high yield \\
\hline
\end{tabular}




\subsection{Water Extraction/Use}

Two water treatments (well-watered (WW): maintained between $85 \%$ and $100 \%$ FC; terminal drought stress (TDS): water withheld until all the available water was used by the plant) were imposed at 40 days after sowing (DAS; V4 stage). Plants under WW conditions were watered every 4 days until maturity. As the tops of the cylinders were covered with black plastic mulch, plant transpiration was measured by successive weighing. The cylinders that contained plants under TDS conditions were weighed every 4- 8 days until maturity. The amount of water uptake by the roots was determined by the loss of the pot weight. The soybean development stages were as described by Fehr et al. [18].

\subsection{Roots Sampling at R2 Stage Under TDS Condition}

When all soybean genotypes reached flowering stage (R2, 70 days after sowing), shoots were cut at $\sim 1 \mathrm{~cm}$ from the soil surface, and roots were collected at every $20 \mathrm{~cm}$ of soil depth. The roots were carefully washed to remove the soil particles in a 0.4-mm sieve and scanned using an EPSON ${ }^{\mathrm{TM}}$ scanner (Epson Inc., Long Beachm, CA, USA). WinRhizo software (Régent Instruments, Inc, Quebec, Canada) was used to analyze the root lengths and root surface areas. Four replicates per cultivar were sampled. After scanning, the roots were dried at $80^{\circ} \mathrm{C}$ in an oven for $24 \mathrm{~h}$ and then weighed.

\subsection{Flower and Pod Tagging}

The days on which each plant showed its first flower and small pod (longer than $2 \mathrm{~mm}$, defined as tagged-pod) were recorded to calculate the flowering and podding time. Every 2 days, new flowers and pods were tagged with the date of the flowering and of the podding noted on the tags so that the flower number and pod number could be determined.

\subsection{Harvest}

Four replicates per cultivar per treatment were used to determine the yield performance. The whole plants were harvested when the soybeans were at physiological maturity. The leaves on each branch were collected and scanned, as done for the roots. The leaf area was determined using Image J software. Whole plants were divided into stems and pods, then dried at $80^{\circ} \mathrm{C}$ for $24 \mathrm{~h}$ in a forced-draught oven and weighed. The water use for the whole life cycle was obtained by adding water from sowing to physiological maturity. Water use efficiency for grain yield $\left(W_{U} E_{G}\right)$ is given as grain yield/water use.

\subsection{Statistical Analysis}

The data used in the tables and figures are the means of four replicates in the pot experiments. The data were analyzed in GenStat 17th Edition (VSN International Ltd., Rothamsted, England) using a two-way analysis of variance (ANOVA). The water treatments and genotypes were used as fixed factors, and the random factor was the replicate.

\section{Results}

\subsection{Yield Performance}

The mean temperature and the precipitation during the growing season in 2014 were $16.4{ }^{\circ} \mathrm{C}$ and $211.9 \mathrm{~mm}$, respectively (Table 2). In the WW treatment, the average grain yield across the new soybean cultivars was significantly higher $\left(18.7 \mathrm{vs.} 15.1 \mathrm{~g} \mathrm{plant}^{-1}\right)$ than the average grain yield across old soybean cultivars; the four old cultivars failed to produce a measurable yield, but only one modern cultivar (J21) failed to produce a yield under TDS (Table 3). The average grain number across the new soybean cultivars was significantly lower (132 vs. 198 plant $\left.^{-1}\right)$, while the average pod dry weight (30.1 vs. $\left.26.9 \mathrm{~g} \mathrm{plant}^{-1}\right)$, the average hundred-grain weight ( 14.9 vs. $\left.7.9 \mathrm{~g}\right)$, and the average water use efficiency for grain yield $\left(\mathrm{WUE}_{\mathrm{G}}, 0.54\right.$ vs. 0.31$)$ were significantly higher than the old soybean cultivars under the WW condition (Table 3). The new soybean cultivars ZH and JD had the lowest pod dry 
weight and grain number under the WW condition, while they had the highest grain yield under TDS (Table 3).

Table 2. Monthly mean temperature and precipitation during the growing season in 2014 .

\begin{tabular}{ccc}
\hline Month & Monthly Mean Temperature $\left({ }^{\circ} \mathbf{C}\right)$ & Monthly Precipitation $(\mathbf{m m})$ \\
\hline April & 14.1 & 1.2 \\
May & 13.9 & 32.6 \\
June & 18.5 & 38.2 \\
July & 19.3 & 42.5 \\
August & 19.4 & 42.8 \\
September & 13.4 & 54.6 \\
\hline
\end{tabular}

Table 3. The pod dry weight (PW, g plant $\left.{ }^{-1}\right)$, grain number (GN, plant $\left.{ }^{-1}\right)$, grain yield $\left(G Y\right.$, g plant $\left.^{-1}\right)$, hundred-grain weight (HGW, g), and water use efficiency for grain yield (WUE $\mathrm{G}_{\mathrm{G}} \mathrm{g} \mathrm{L}^{-1}$ ) in eight soybean cultivars (Huangsedadou (HD), Longxixiaohuangpi (LX), Bailudou (BLD), Xiaoheidou (XHD), Jindou 19 (J19), Jidou 12 (Ji), Zhonghuang (ZH), and Jindou 21 (J21)) under well-watered (WW) and terminal drought stress (TDS) conditions.

\begin{tabular}{ccccccc}
\hline WT & cv. & PW & GN & GY & HGW & WUE $_{\mathbf{G}}$ \\
\hline WW & HD & 29.6 & 185.8 & 15.3 & 8.2 & 0.31 \\
& LX & 27.5 & 217.3 & 16.0 & 7.3 & 0.32 \\
& BLD & 22.9 & 142.3 & 13.5 & 9.6 & 0.30 \\
& XHD & 27.8 & 247.3 & 15.5 & 6.3 & 0.31 \\
& J19 & $\mathbf{2 8 . 9}$ & $\mathbf{1 1 1 . 5}$ & $\mathbf{1 9 . 6}$ & $\mathbf{1 7 . 6}$ & $\mathbf{0 . 6 3}$ \\
& Ji & $\mathbf{3 3 . 0}$ & $\mathbf{1 1 7 . 0}$ & $\mathbf{1 9 . 3}$ & $\mathbf{1 6 . 6}$ & $\mathbf{0 . 4 4}$ \\
& ZH & $\mathbf{2 5 . 4}$ & $\mathbf{1 1 1 . 3}$ & $\mathbf{1 6 . 6}$ & $\mathbf{1 5 . 1}$ & $\mathbf{0 . 7 0}$ \\
& J21 & $\mathbf{3 2 . 9}$ & $\mathbf{1 8 9 . 3}$ & $\mathbf{1 9 . 4}$ & $\mathbf{1 0 . 3}$ & $\mathbf{0 . 3 7}$ \\
\hline TDS & HD & 0.0 & 0.0 & 0.0 & 0.0 & 0 \\
& LX & 0.0 & 0.0 & 0.0 & 0.0 & 0 \\
& BLD & 0.1 & 0.5 & 0.05 & 0.9 & 0 \\
& XHD & 0.0 & 0.0 & 0.0 & 0.0 & 0 \\
& J19 & $\mathbf{6 . 8}$ & $\mathbf{4 0 . 0}$ & $\mathbf{3 . 6}$ & $\mathbf{8 . 8}$ & $\mathbf{0 . 4 3}$ \\
& Ji & $\mathbf{0 . 9}$ & $\mathbf{2 . 5}$ & $\mathbf{0 . 1}$ & $\mathbf{4 . 8}$ & $\mathbf{0 . 0 1}$ \\
& ZH & $\mathbf{4 . 6}$ & $\mathbf{3 1 . 5}$ & $\mathbf{2 . 4}$ & $\mathbf{7 . 6}$ & $\mathbf{0 . 2 7}$ \\
& J21 & $\mathbf{0 . 0}$ & $\mathbf{0 . 0}$ & $\mathbf{0 . 0}$ & $\mathbf{0 . 0}$ & $\mathbf{0}$ \\
\hline & LSD $_{0.05}$ & 3.6 & 25.0 & 2.1 & 2.4 & 0.11 \\
\hline
\end{tabular}

\subsection{Water Use Under Two Water Regimes}

Among the eight cultivars, the water use varied under the WW treatment; the soybean cultivar J21 exhibited the highest water use, whereas ZH used the lowest amount of water under the WW treatment. The average water use across the new soybean cultivars was significantly less $(36 \pm 3 \mathrm{~L}$ plant $^{-1}$ vs. $47 \pm 1 \mathrm{~L} \mathrm{plant}^{-1}$ ) than the landraces under the WW treatment (Figure 1). All cultivars used the same amount of water under TDS. The average water use before flowering across the new soybean cultivars $\left(3.6 \pm 0.3\right.$ vs. $\left.4.1 \pm 0.1 \mathrm{~L} \mathrm{plant}^{-1}\right)$ was less, while the average water use after flowering (vs. $4.3 \pm 0.3 \mathrm{~L} \mathrm{plant}^{-1}$ ) was more than the old soybean genotypes under TDS. In the WW treatment, the average water use before $\left(3.7 \pm 0.6\right.$ vs. $\left.5.8 \pm 0.2 \mathrm{~L} \mathrm{plant}^{-1}\right)$ and after flowering $(32.8 \pm 2.3 \mathrm{vs}$. $41.2 \pm 0.7 \mathrm{~L} \mathrm{plant}^{-1}$ ) was less than the landraces under WW conditions. 

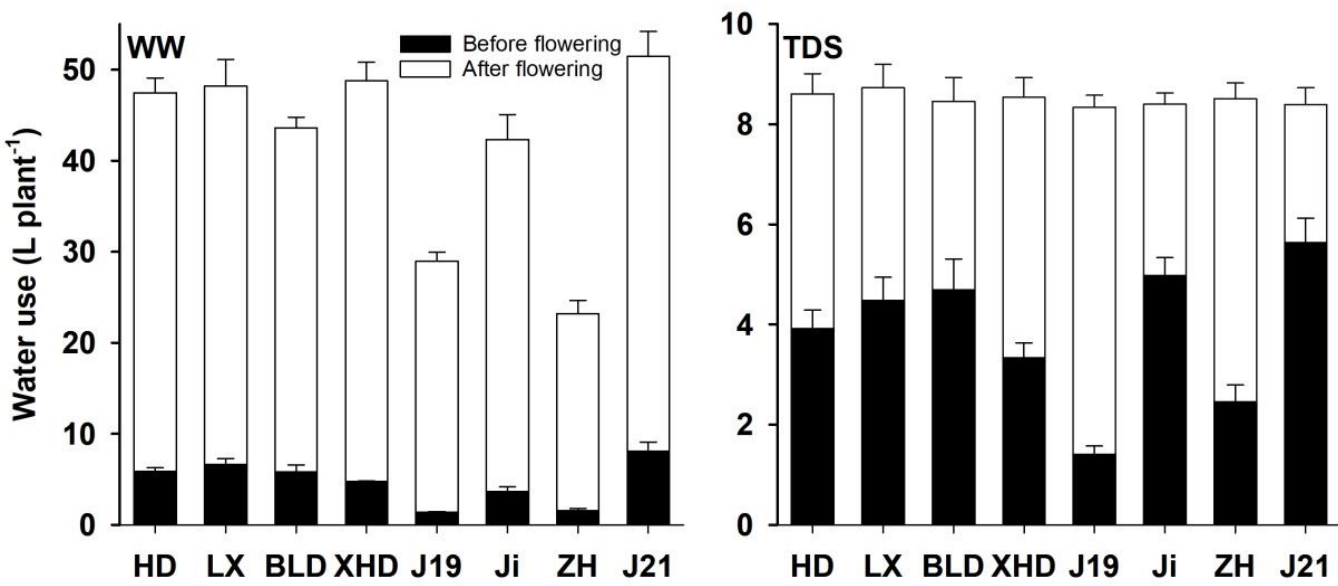

Figure 1. The water use before and after flowering in eight soybean cultivars (Huangsedadou (HD), Longxixiaohuangpi (LX), Bailudou (BLD), Xiaoheidou (XHD), Jindou 19 (J19), Jidou 12 (Ji), Zhonghuang $(\mathrm{ZH})$, and Jindou 21 (J21)) under well-watered (WW, left) and terminal drought stress (TDS, right) conditions. Values are means $\pm \mathrm{SE}$.

\subsection{Flower and Pod Number, and Flowering and Podding Period Under WW and TDS}

The new soybean cultivars on average produced fewer flowers over a shorter flowering period than the old soybean cultivars under WW conditions (Figure 2A,C). Water stress significantly reduced the flower number that in the new soybean cultivars on average was smaller than that in the old soybean cultivars under TDS. Moreover, the average flowering period in the new soybean cultivars (40 days vs. 47 days) was shorter than that in the old cultivars. Water use during the flowering period was significantly positively correlated with the flower number under WW $\left(R^{2}=0.51 ; p<0.001\right)$ and $\operatorname{TDS}\left(R^{2}=0.29 ; p=0.0013\right)$ conditions (Figure 3$)$.

The tagged-pod number average across the new soybean cultivars was lower, and the average podding period across new soybean cultivars was shorter than that in the landraces under WW conditions (Figure 2B-D). TDS significantly reduced the pod number and the podding period; the two new cultivars, $\mathrm{ZH}$ and J19, produced more pods over a longer period than the old cultivars under TDS (Figure 2B-C). The average water use during podding across the new cultivars was lower under WW conditions but higher under TDS than in the old soybean cultivars; moreover, water use during the podding period was significantly correlated to the pod number under WW $\left(R^{2}=0.45 ; p<0.001\right)$ and $\operatorname{TDS}\left(R^{2}=0.67 ; p<0.001\right)$ conditions (Figure 3$)$.
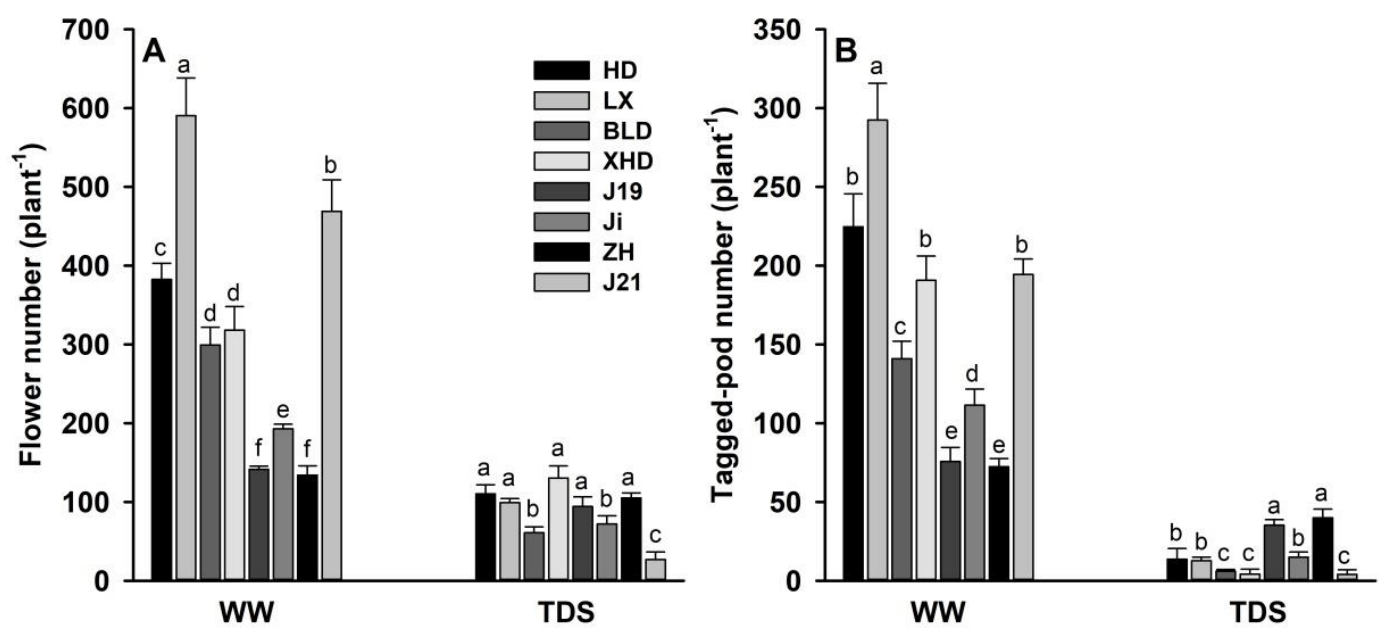

Figure 2. Cont. 

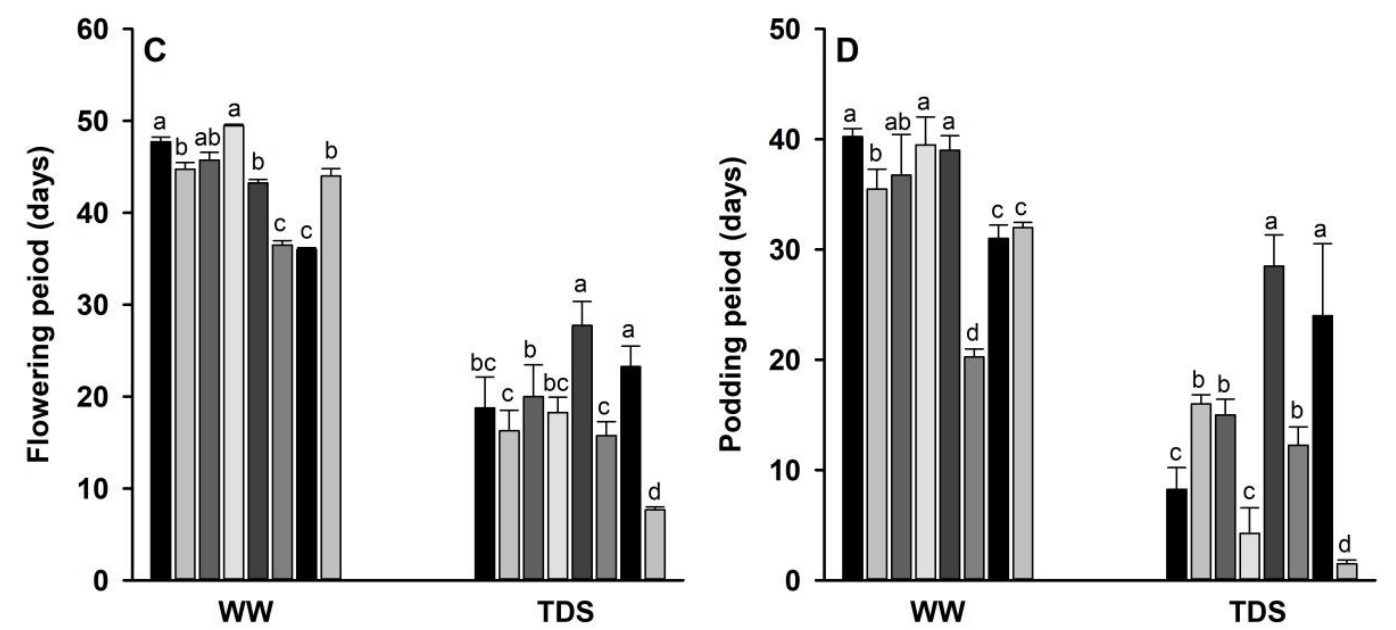

Figure 2. The (A) flower and (B) tagged-pod number, and (C) flowering and (D) podding period in the eight soybean cultivars (Huangsedadou (HD), Longxixiaohuangpi (LX), Bailudou (BLD), Xiaoheidou (XHD), Jindou 19 (J19), Jidou 12 (Ji), Zhonghuang (ZH), and Jindou 21 (J21)) under well-watered (WW) and terminal drought (TDS) conditions. Values are means \pm SE. The different letter in the same panel means significantly different at $p=0.05$.
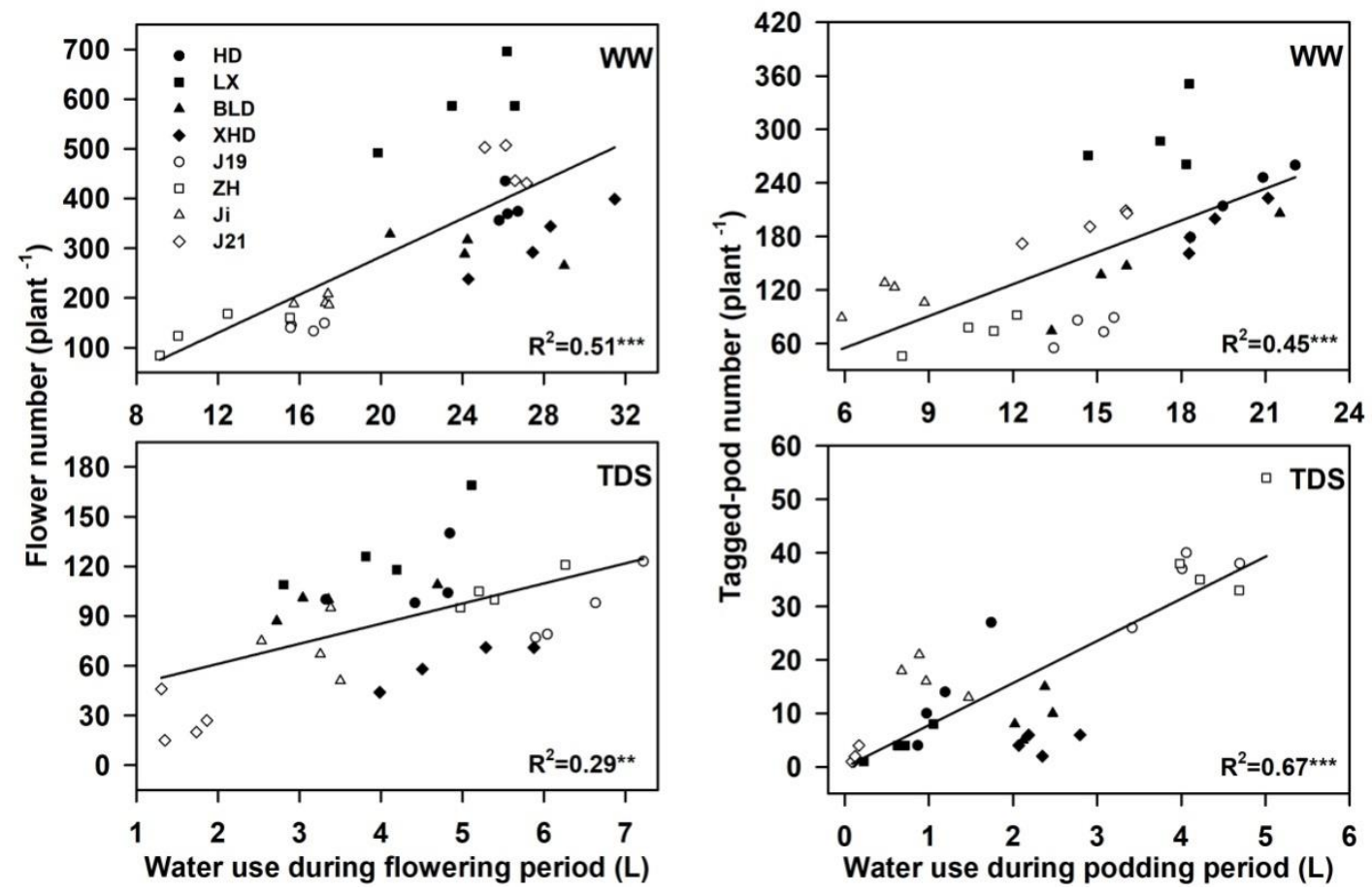

Figure 3. The relationship between the water use during flowering and flower number (Left), the water use during podding, and the tagged-pod number (Right) in eight soybean cultivars (Huangsedadou (HD), Longxixiaohuangpi (LX), Bailudou (BLD), Xiaoheidou (XHD), Jindou 19 (J19), Jidou 12 (Ji), Zhonghuang $(\mathrm{ZH})$, and Jindou 21 (J21)) under well-watered (WW) and terminal drought stress (TDS) conditions. ${ }^{* *} p<0.01,{ }^{* *} p<0.001$.

\subsection{Canopy Architecture Under Both Water Regimes at Harvest}

The canopy architecture varied among the eight soybean cultivars at R2 and at maturity (Figure 4). The number of leaves on the main stem and the branch number varied from 15-24 to 4-10 at R2, and from 15-24 to 3-10 at maturity, respectively. Soybean cultivar LX had the highest and Ji the lowest leaf numbers on the main stem, while J19 had the lowest branch number under WW conditions at maturity 
(Figure 4). The leaf areas on the main stem and branch were different under each water regime. In TDS treatment, the leaf area on the main stem varied between 1020 and $1615 \mathrm{~cm}^{2}$ plant $^{-1}$, while the leaf area on the branch varied from 822 to $2620 \mathrm{~cm}^{2}$ plant $^{-1}$ at the R2 stage; the leaf area on the main stem and branches varied from 1746 to $2603 \mathrm{~cm}^{2}$ plant ${ }^{-1}$ and 599 to $5109 \mathrm{~cm}^{2}$ plant $^{-1}$ at maturity under WW conditions (Figure 5).
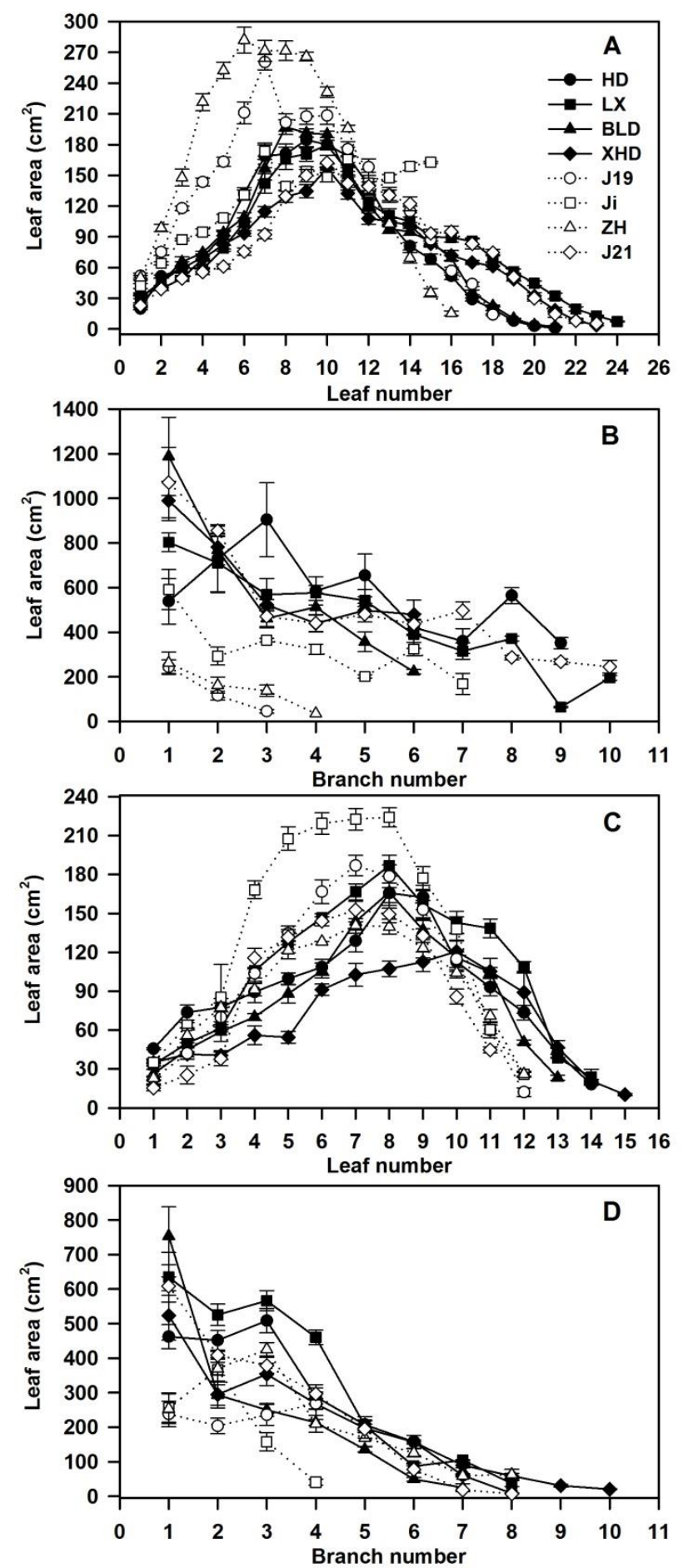

Figure 4. The leaf area distributed on the main stem and branches in eight soybean cultivars (Huangsedadou (HD), Longxixiaohuangpi (LX), Bailudou (BLD), Xiaoheidou (XHD), Jindou 19 (J19), Jidou 12 (Ji), Zhonghuang (ZH), and Jindou 21 (J21)) under well-watered (WW, A,B) at maturity and terminal drought stress (TDS, C,D) conditions at the R2 stage. Values are means \pm SE. 

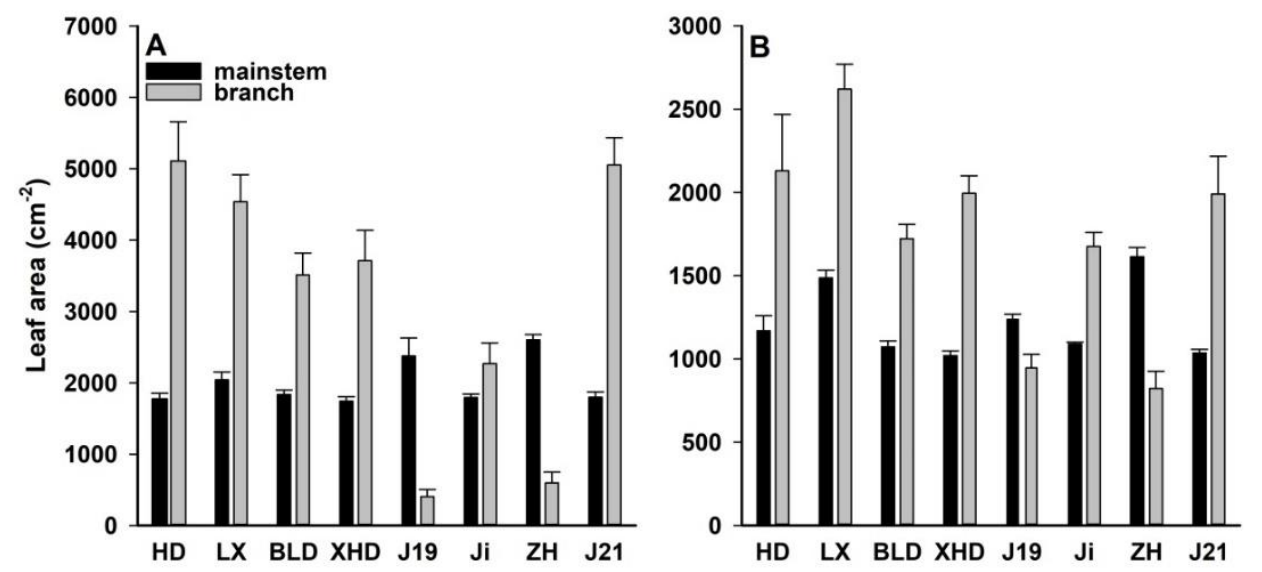

Figure 5. The leaf area on the main stem and branches in eight soybean cultivars (Huangsedadou (HD), Longxixiaohuangpi (LX), Bailudou (BLD), Xiaoheidou (XHD), Jindou 19 (J19), Jidou 12 (Ji), Zhonghuang (ZH), and Jindou 21 (J21)) under well-watered (WW, A) at maturity and terminal drought stress (TDS, B) conditions at the R2 stage. Values are means \pm SE.

\subsection{Root Morphology at R2 stage}

The root was sampled at the full flowering stage in TDS conditions. The root length density and root surface area were different at the same soil depth; the new soybean cultivars on average had a lower special root length and surface area than the old cultivars (Figure 6A,B). The root length density and root surface area were lowest at a $0.8 \mathrm{~m}$ soil depth; LX had the highest root length density and root surface area while $\mathrm{ZH}$ had the lowest root length density (Figure 6).

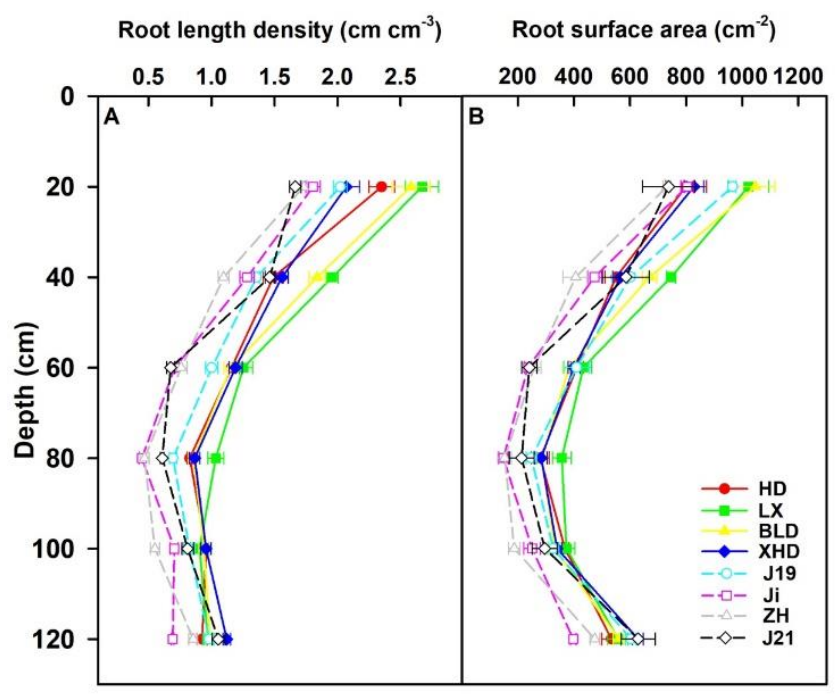

Figure 6. The root length density (A) and root surface area (RSA, B) distributed at different distances from the surface in eight soybean cultivars (Huangsedadou (HD), Longxixiaohuangpi (LX), Bailudou (BLD), Xiaoheidou (XHD), Jindou 19 (J19), Jidou 12 (Ji), Zhonghuang (ZH), and Jindou 21 (J21)) at the full flowering stage under terminal drought stress (TDS). Values are means \pm SE.

\section{Discussion}

\subsection{Root Size, Canopy Architecture, and Water Use}

Water is taken up by the roots and lost from the leaves by transpiration. Roots are the main water- and nutrient-absorbing organs, and a number of root-related traits, such as root distribution and density, have been proposed as indicators of drought tolerance in soybean [14-16]. In our study, the soybean cultivars that used less water had a lower root length density and root surface area at the 
same soil depth but a higher grain yield than the soybean cultivars with higher water use, indicating that root morphology had evolved in the water-saving mechanism. The lower root length density and root surface area could be employed as drought tolerance traits in soybean because the low root length density and/or root surface area could use the water slowly [17]. This result was contrary to previous studies, which proposed that extensive root development was the main drought avoidance trait that contributed to seed yield under TDS conditions $[2,19,20]$. One possible reason was that the extensive root development could increase water uptake and contribute to the high yield of a single plant yield under TDS, but extensive root development would consume the water fast, which has a negative effect on soybean yield under water stress [21].

Crop water demand can be reduced by decreasing the leaf area, which can be achieved by lowing the tillering [22], the leaf number per culm, and/or individual leaf size [23]. In our study, we found that the two soybean cultivars ZH and JD showed the least water use and had the lowest leaf area, which indicates that reducing the leaf area was the main factor that contributed to the water-saving mechanism. The correlation analysis showed that the leaf area on the main stem was significantly negatively correlated with the water use $\left(R^{2}=0.84, p<0.001\right.$; data not shown), but the leaf area on the branches was significantly positively correlated with water use $\left(R^{2}=0.87, p<0.001\right.$; data not shown). Aside from $\mathrm{ZH}$ and JD with the least water use, they displayed higher leaf areas on the main stem than branches, while these two cultivars had the lowest branch number at two development stages. Thus, the leaf area on the branches was the main driver of the water use, and reducing the branch number was the main factor that determined the leaf area on branches. In addition, our previous studies showed that $\mathrm{ZH}$ and JD had higher grain yields than the old soybean cultivars under both WW and water deficit conditions $[17,24,25]$, which was also observed in this study. Thus, reducing the canopy size by lowering the branch number could reduce water demand and improve yield performance under drought; therefore, a lower branch number may be considered a useful trait in drought-tolerance selection.

\subsection{Water Use, Flower and Pod Development, and Yield and Drought Adaptation}

In our study, we found that the water use patterns were different among the eight soybean cultivars, and reducing water use before flowering by reducing the root size and canopy size improved drought adaptation after flowering because reducing the water use before flowering could increase the water available after flowering under terminal drought stress $[9,17]$. The two soybean cultivars, $\mathrm{ZH}$ and J19, used less water but produced a grain yield, whereas the other six soybean cultivars used more water but produced little or no yield under TDS. Thus, reducing pre-flower water use increases post-anthesis drought adaptation [12]. Under WW treatment, although average water use before and after flowering across the new soybean cultivars was less than across the old soybean cultivars, the ratio of water use before flowering in total water use across the old soybean cultivars was higher $(12.3 \%$ vs. $9.0 \%$ ) than across the new soybean cultivars, indicating that the water partition was changed by traditional soybean breeding. Moreover, the new soybean cultivars showed a lower water use but the highest grain yield. Thus, reducing water use while increasing the ratio of water used after flowering had benefits for yield performance.

How does the water use affect the grain yield? The formation of flowers and pods was a perquisite for the yield [9]. The correlation analysis showed that water use during flowering or podding significantly correlated with the flower or pod number under both WW and TDS conditions, indicating that increasing water use during the reproductive stage benefited the production of flowers and pods under both WW and TDS conditions. Thus, the change of water use pattern was associated with the changing of the flower and pod number, which contributed to the final grain yield.

\section{Conclusions}

In this study, we found that yield performance and drought adaptation were associated with water uptake at the flowering and podding stage and water use before flowering. The leaf area on 
the branches was the main driver of the water use, and reducing the branch number was the main factor that determined the leaf area on branches. Reducing the canopy size by lowering the branch number could reduce water demand and improve yield performance under a drought. Conserved water use before flowering would allow more water use after flowering and produce more flowers and pods, thus giving a higher grain yield. Conserved water use was associated with changing canopy architecture and root traits.

Author Contributions: The listed authors contributed to this work as described in the following: M.L. was responsible for the conceptualization and gave the concepts of this work; J.H. designed whole experiments and provided financial support; X.-B.G. did the experiments and prepared the original draft; C.G. did part of the experimental and data creation; M.L., J.H., F.-M.L., reviewed and edited this manuscript, methodology, and formal analysis. All authors have read and agreed to the published version of the manuscript.

Acknowledgments: This work was supported by the Guizhou Science and Technology Support Program Project (Qiankehezhichen (2016) 2570, (2019) 2399), the National Key Research and Development Program of China (2018YFC1802602), the Key Laboratory of Soil Quality Safety and the Regulation of Water and Fertilizer of Guizhou Province (Qianjiaohe KY (2016) 001), the Guizhou Provincial Biology First-Class Subject Construction Project (GNYL (2017) 009), the Provincial Nation-class Discipline of Biology Foundation, and the National Natural Science Foundation of China (NSFC: Grant No. 31960616).

Conflicts of Interest: The authors declare no conflict of interest.

\section{References}

1. Manavalan, L.P.; Guttikonda, S.K.; Tran, L.S.P.; Nguyen, H.T. Physiological and molecular approaches to improve drought resistance in Soybean. Plant Cell Physiol. 2009, 50, 1260-1276. [CrossRef] [PubMed]

2. Turner, N.C.; Wright, G.C.; Siddique, K.H.H. Adaptation of grain legumes (pulses) to water-limited environments. Adv. Agron. 2001, 71, 193-231.

3. Merah, O. Potential importance of water status traits for durum wheat improvement under Mediterranean conditions. J. Agric. Sci. 2001, 137, 139-145. [CrossRef]

4. Koester, R.P.; Skoneczka, J.A.; Cary, T.R.; Diers, B.W.; Ainsworth, E.A. Historical gains in soybean (Glycine $\max$ Merr.) seed yield are driven by linear increases in light interception, energy conversion, and partitioning efficiencies. J. Exp. Bot. 2014, 65, 3311-3321. [CrossRef]

5. Leport, L.; Turner, N.C.; Davies, S.L.; Siddique, K.H.M. Variation in pod production and abortion among chickpea cultivars under terminal drought. Eur. J. Agron. 2006, 24, 236-246. [CrossRef]

6. Fang, X.W.; Turner, N.C.; Yan, G.J.; Li, F.M.; Siddique, K.H.M. Flower numbers, pod production, pollen viability, and pistil function are reduced and flower and pod abortion increased in chickpea (Cicer arietinum L.) under terminal drought. J. Exp. Bot. 2010, 61, 335-345. [CrossRef]

7. Kholova, J.; Hash, C.T.; Kakkera, A.; Kocova, M.; Vadez, V. Constitutive water-conserving mechanisms are correlated with the terminal drought tolerance of pearl millet [Pennisetum glaucum (L.) R. Br.]. J. Exp. Bot. 2010, 61, 369-377. [CrossRef]

8. Kholova, J.; Hash, C.T.; Kumar, P.L.; Yadav, R.S.; Kocova, M.; Vadez, V. Terminal drought-tolerant pearl millet [Pennisetum glaucum (L.) R. Br.] have high leaf ABA and limit transpiration at high vapour pressure deficit. J. Exp. Bot. 2010, 61, 1431-1440. [CrossRef]

9. Zaman-Allah, M.; Jenkinson, D.M.; Vadez, V. A conservative pattern of water use, rather than deep or profuse rooting, is critical for the terminal drought tolerance of chickpea. J. Exp. Bot. 2011, 62, 4239-4252. [CrossRef]

10. Belko, N.; Zaman-Allah, M.; Cisse, N.; Diop, N.N.; Zombre, G.; Ehlers, J.D.; Vadez, V. Lower soil moisture threshold for transpiration decline under water deficit correlates with lower canopy conductance and higher transpiration efficiency in drought-tolerant cowpea. Funct. Plant Biol. 2012, 39, 306-322. [CrossRef]

11. Vadez, V.; Kholova, J.; Yadav, R.S.; Hash, C.T. Small temporal differences in water uptake among varieties of pearl millet (Pennisetum glaucum (L.) R. Br.) are critical for grain yield under terminal drought. Plant Soil 2013, 371, 447-462. [CrossRef]

12. Borrell, A.K.; Mullet, J.E.; George-Jaeggli, B.; van Oosterom, E.J.; Hammer, G.L.; Klein, P.E.; Jordan, D.R. Drought adaptation of stay-green sorghum is associated with canopy development, leaf anatomy, root growth, and water uptake. J. Exp. Bot. 2014, 65, 6251-6263. [CrossRef] [PubMed]

13. Van Oosterom, E.J.; Borrell, A.K.; Deifel, K.S.; Hammer, G.L. Does increased leaf appearance rate enhance adaptation to postanthesis drought stress in sorghum? Crop Sci. 2011, 51, 2728-2740. [CrossRef] 
14. Liu, Y.; Gai, J.Y.; Lu, H.; Wang, Y.J.; Chen, S.Y. Identification of drought tolerant germplasm and inheritance and QTL mapping of related root traits in soybean [Glycine max (L.) Merr.]. Acta Genet. Sin. 2005, 32, 855-863. [PubMed]

15. Wang, M.; Zhang, C.; Ma, T. studies in the drought resistance of seedings in soybean. Chin. J. Oil Sci. 2004, 26, 29-32.

16. Garay, A.; Wilhelm, W. Root system characteristics of two soybean isolines undergoing water stress conditions. Agron. J. 1983, 75, 973-977. [CrossRef]

17. He, J.; Du, Y.L.; Wang, T.; Turner, N.C.; Yang, R.P.; Jin, Y.; Xi, Y.; Zhang, C.; Cui, T.; Fang, X.W.; et al. Conserved water use improves the yield performance of soybean (Glycine max (L. Merr.)) under drought. Agric. Water Manag. 2017, 179, 236-245. [CrossRef]

18. Fehr, W.; Caviness, C.; Burmood, D.; Pennington, J. Stage of development descriptions for soybeans, Glycine $\max$ (L.). Merrill. Crop Sci. 1971, 11, 929-931. [CrossRef]

19. Subbarao, G.V.; Johansen, C.; Slinkard, A.E.; Rao, R.C.N.; Saxena, N.P.; Chauhan, Y.S. Strategies for improving drought resistance in grain legumes. Crit. Rev. Plant Sci. 1995, 14, 469-523. [CrossRef]

20. Kashiwagi, J.; Krishnamurthy, L.; Upadhyaya, H.D.; Krishna, H.; Chandra, S.; Vadez, V.; Serraj, R. Genetic variability of drought-avoidance root traits in the mini-core germplasm collection of chickpea (Cicer arietinum L.). Euphytica 2005, 146, 213-222. [CrossRef]

21. Sinclair, T.R.; Messina, C.D.; Beatty, A.; Samples, M. Assessment across the United States of the benefits of altered soybean drought traits. Agron. J. 2010, 102, 475. [CrossRef]

22. Kim, H.K.; Luquet, D.; van Oosterom, E.; Dingkuhn, M.; Hammer, G. Regulation of tillering in sorghum: Genotypic effects. Ann. Bot. 2010, 106, 69-78. [CrossRef]

23. Borrell, A.K.; Hammer, G.L.; Douglas, A.C. Does maintaining green leaf area in sorghum improve yield under drought? I. Leaf growth and senescence. Crop Sci. 2000, 40, 1026-1037. [CrossRef]

24. He, J.; Du, Y.L.; Wang, T.; Turner, N.C.; Xi, Y.; Li, F.M. Old and new cultivars of soya bean (Glycine max L.) subjected to soil drying differ in abscisic acid accumulation, water relations characteristics and yield. J. Agron. Crop Sci. 2016, 202, 372-383. [CrossRef]

25. He, J.; Jin, Y.; Turner, N.C.; Li, F.M. Irrigation during flowering improves subsoil water uptake and grain yield in rainfed soybean. Agronomy 2020, 10, 120. [CrossRef] 